\title{
Methods for detecting lupus anticoagulants and their relation to thrombosis and miscarriage in patients with systemic lupus erythematosus
}

\author{
D Ferro, M Saliola, C Quintarelli, G Valesini, S Basili, A M Grandilli, M S Bonavita, \\ F Violi
}

\begin{abstract}
Aims: To examine the sensitivity and specificity to past thrombotic events of four different coagulation tests, which screen for lupus anticoagulant (LA), and of anticardiolipin antibodies in patients with systemic lupus erythematosus.

Methods: Fifty three consecutive patients with systemic lupus erythematosus were studied of whom three males and 21 females, aged $21-60$ years, had a history of venous and arterial thrombosis, or miscarriage, or both. Activated partial thromboplastin time (aPTT), dilute Russell's viper venom time (dRVVT), kaolin clotting time (KCT), dilute aPTT and the circulating titre of anticardiolipin antibodies were investigated in the two groups of patients and in 20 healthy control subjects.

Results: The prolonged dilute aPTT was more sensitive to thromboses or miscarriages, or both than dRVVT $(p<0.05)$, KCT $(p<0.01)$, and aPTT $(p<0.001)$. No significant differences in specificity were found among aPTT $(100 \%)$, dRVVT (93\%), KCT (93\%) and dilute aPTT $(86.2 \%)$; but aPTT and dRVVT were significantly more specific (p $<0.01, p<0.05$, respectively) than anticardiolipin antibodies.

Conclusions: The study shows a strong association between lupus anticoagulant and thrombosis when a very sensitive test such as the dilute aPTT is used. The combination of this assay with a very specific test such as dRVVT might enable patients with SLE at high risk of thrombosis to be identified.
\end{abstract}

Institute of Clinical Medicine I, University of Rome "La Sapienza," Rome, Italy

D Ferro

M Saliola

C Quintarelli

G Valesini

$S$ Basili

A M Grandilli

M S Bonavita

F Violi

Correspondence to: Dr Francesco Violi, Università degli Studi di Roma "La Sapienza", Istituto di I Clinica medica generale e Terapia Medica, Policlinico Umberto I, 00181, Rome, Italy

Accepted for publication 5 September 1991 with drugs regimens, following viral infections including AIDS, in haematological malignant diseases, and in apparently healthy subjects, ${ }^{4-6}$ it was initially described in autoimmune disease and, in particular, in patients with systemic lupus erythematosus (SLE). ${ }^{7}$

Previous reports have suggested the prevalence of lupus anticoagulant in patients with SLE to be between $10 \%$ and $15 \%,{ }^{8-10}$ but other recent studies have found the prevalence to be 21 to $65 \% .^{11-13}$ This discrepancy may depend on the fluctuation of lupus anticoagulant due to disease activity or treatment, ${ }^{14}{ }^{15}$ but it is more probably due to the different sensitivites of the various tests and reagents used to verify the presence of lupus anticoagulant. ${ }^{16-18}$ More recently, some authors have also suggested possible laboratory heterogeneity among "lupus anticoagulants". ${ }^{19-21}$

The routinely used coagulation tests in which phospholipids are added to the test system, especially activated partial thromboplastin time (aPTT), have been found by different authors to be insufficiently sensitive to the presence of lupus anticoagulant. ${ }^{22}$ The reduction or the elimination of exogenous phospholipids in the dilute Russell's viper venom time (dRVVT) and kaolin clotting time (KCT), respectively, actually increased the sensitivity to lupus anticoagulant. ${ }^{122}$ The positivity of lupus anticoagulant is associated with a tendency to thromboembolic events; thrombosis is common in patients with lupus anticoagulant, where it ranges from $25 \%$ $35 \%,{ }^{25}$ although some authors have found a higher prevalence. ${ }^{7126}$ Lupus anticoagulant positive women also have a high risk of recurrent abortions due to thrombosis of the placental and decidual vessels. ${ }^{27} 28$

The variability in the prevalence of thrombotic phenomena in such patients could depend on the differing capacity of the tests to detect lupus anticoagulant. In fact, it seems that a stronger association can be found between lupus anticoagulant and thrombosis using tests which are more sensitive to and specific for the presence of lupus anticoagulant. ${ }^{22} 2930$

The aim of this study was to compare the respective sensitivity and specificity to thrombotic episodes of four coagulation tests (aPTT, dRVVT, KCT, dilute aPTT), previously shown to have varying capacities to detect lupus anticoagulant. ${ }^{122} 2431$ Furthermore, we evaluated the titre of circulating anticardiolipin antibodies which have been reported as being strongly associated with lupus anticoagulant ${ }^{3233}$ and measurable by several immunoassays. ${ }^{34} 35$ 


\section{Methods}

The study was carried out on 53 consecutive patients (eight males, 45 females, aged 16-60 years) with SLE defined according to the American Rheumatosis Association's criteria. ${ }^{36}$ They were examined in our Institute between January 1988 and June 1990 after informed written consent had been obtained. Twenty four of these patients (three males, 21 females, aged 21-60 years) had a history of venous and arterial thrombosis or miscarriages occurring over the previous one to 10 years. In the thrombotic patient group the average duration of SLE was seven years (range two to 11). Twenty nine patients (five males, 24 females, aged 16-58 years) had no history of thromboses or miscarriages. In these patients the clinical history of SLE had begun, on average, eight years previously (range two to 19 years). The two groups of patients were similar with respect to age, sex, and disease activity. Forty four patients ( 21 in the group with a history of thrombosis, 23 in the group without thrombotic episodes) were taking prednisone $(12.5$ $50 \mathrm{mg} /$ day), methylprednisolone (4-24 mg/ day), or methotrexate (20 mg weekly). None of the patients under examination had undergone anticogulant, antiaggregant, or fibrinolytic treatment during the month before the study. Blood samples collected in one tenth volume of sodium citrate $(0 \cdot 13 \mathrm{M})$, were taken from patients after a 12 hour fast. Platelet poor plasma (PPP) was obtained by double high speed centrifugation at $5000 \times g$ for $10 \mathrm{~min}$ utes at room temperature. Four different coagulation tests were used: aPTT, dRVVT, KCT and dilute aPTT. All patient samples giving abnormal results were re-performed by mixing fresh patient's plasma in a 1:1 ratio with fresh pooled normal plasma, to allow for replacement of any factory deficiency. If the time remained prolonged the test was validated as abnormal. The activated PTT was carried out by incubating, for three minutes at $37^{\circ} \mathrm{C}$, $0.1 \mathrm{ml}$ of plasma sample with $0.1 \mathrm{ml}$ of standard phospholipid mixture and activator (Activated Thrombofax, Ortho Diagnostics; Milan); $0.1 \mathrm{ml}$ of $0.025 \mathrm{M}$ of calcium chloride was then added and the clotting time recorded on a Schnitger und Gross coagulometer. ${ }^{29}$ aPTT was expressed as patient:normal ratio (normal values of $\leq 1 \cdot 2$ ).

The dilute Russell's viper venom time (dRVVT) was carried out by incubating, for three minutes at $37^{\circ} \mathrm{C}, 0.1 \mathrm{ml}$ of Russell's viper venom (Wellcome Diagnostics, Dartford, England) diluted 1 in 200 in TRIS buffered saline $(0.15 \mathrm{~mol} / 1$ sodium chloride, $0.02 \mathrm{~mol} / 1$ TRIS, $\mathrm{pH} 7 \cdot 5), 0 \cdot 1 \mathrm{ml}$ of diluted phosphilipid reagent (Thrombofax, Ortho Diagnostics, Milan; diluted 1 in 8 in TRIS-buffered saline), and $0.1 \mathrm{ml}$ of plasma sample. Clotting time was recorded after the addition of $0.1 \mathrm{ml}$ of $0.025 \mathrm{M}$ calcium chrloride. ${ }^{24}$ The normal range, determined on 20 fresh normal plasmas (20 healthy subjects, five males, 15 females, aged 20-58 years) was 26.4 (SD 1.4) seconds. Clotting time longer than 30 seconds (mean + $2.5 \mathrm{SD}$ of controls) was considered to be abnormal.
Kaolin clotting time, originally described by Margolis, ${ }^{37}$ was measured by incubating, for two minutes at $37^{\circ} \mathrm{C}, 0.05 \mathrm{ml}$ of $2 \%$ diluted kaolin with $0.1 \mathrm{ml}$ of plasma sample; clotting time was recorded by adding $0.1 \mathrm{ml}$ of $0.025 \mathrm{M}$ calcium chloride. ${ }^{12}$ The normal range, determined on 20 fresh normal plasmas, was 48.8 (SD 8.0) seconds. Clotting time of 65 seconds or greater (mean $+2 \mathrm{SD}$ of controls) was considered to be abnormal.

The dilute aPTT, assessed by serial phospholipid dilutions, was performed as follows: $0.1 \mathrm{ml}$ of plasma sample was incubated for three minutes at $37^{\circ} \mathrm{C}$ with $0.1 \mathrm{ml}$ of kaolin suspension diluted 1 in 15 (Boehringer Mannheim, Germany) and $0.1 \mathrm{ml}$ or Thrombofax (Ortho Diagnostics; Milan) diluted in two different ratios $(1: 5$ and $1: 80)$ with veronal buffer at pH 7.4. Clotting time was recorded after the addition of $0.1 \mathrm{ml}$ of $0.025 \mathrm{M}$ calcium chloride. ${ }^{38}$ In the 20 healthy subjects the difference between 1 in 80 and 1 in 5 Thrombofax dilutions was 9 (SD 2.8) seconds.

Dilute aPTT was considered abnormal if the difference between 1 in 80 and 1 in 5 Thrombofax dilutions was more than 15 seconds (mean +2 SD of controls). To confirm if the abnormality of all the phospholipid dependent tests was due to the presence of lupus anticoagulant, $0.1 \mathrm{ml}$ of $0.05 \mathrm{mM}$ phosphatidylserine-phosphatidylcholine (PS-PC) liposomes were added to the plasma phospholipid mixture to neutralise the anticoagulant effect of antiphospholipid antibodies, as previously described. ${ }^{39}$

For the evaluation of the anticardiolipin antibodies an enzyme linked immunosorbent assay (ELISA) was used. This method was validated in an international workshop and is outlined below. ${ }^{40}$ Briefly, 95-well, flat-bottomed, rigid polystyrene electroimmunoassay microtitration plates (Dynatech) are coated (30 $\mu \mathrm{l} /$ well) with bovine heart cardiolipin (Sigma Chemical Company, St Louis, Missouri) diluted in ethanol. The ethanol is evaporated by leaving the plates uncovered overnight at $4^{\circ} \mathrm{C}$. After the plates have been dried they are washed twice with phosphate buffered saline ( $\mathrm{pH} \mathrm{7 \cdot 3)} 100 \mu \mathrm{l} /$ well. The plates are blocked $(75 \mu /$ well $)$ with $10 \%$ fetal calf serum in phosphate buffered saline for one hour. Aliquots $(50 \mu \mathrm{l})$ of normal human serum, positive control samples, and test samples at 1 in 50 dilution in phosphate buffered saline-fetal calf serum $(10 \%)$ are then added to triplicate wells and incubated for three hours at room temperature. The plates are then washed three times with phosphate buffered saline, and alkaline phosphatase labelled, affinity isolated, goat antihuman IgG or IgM, or both, diluted 1 in 1000 in phosphate buffered saline-fetal calf serum is added $(50 \mu \mathrm{l} /$ well $)$. Plates are incubated for 30 minutes at room temperature. The conjugate is discarded and the plates washed three times with phosphate buffered saline. Substrate $(50 \mu \mathrm{l} /$ well $)$ is then added. The substrate is prepared by adding one tablet of p-nitrophenyl phosphate (Sigma) per 5-6 ml diethanolamine buffer. After addition of substrate the reaction is allowed to take place in the 
dark at $37^{\circ} \mathrm{C}$, and when the highest positive control value reaches an absorbance reading of about 0.8 to 0.9 for both the IgG and IgM samples, the reaction is stopped by adding $3 \mathrm{~N}$ sodium hydroxide $75 \mu \mathrm{l} /$ well. Absorbance is read at $405 \mathrm{~nm}$ using a multiscanner. The results are expressed as the number of standard deviations above the mean in normal human serum (reference value $<3 \mathrm{SD}$ ). Finally, the possible presence of intravascular clotting activation was investigated in all patients by measurement of D-Dimer (Ortho Dimertest, Ortho Diagnostics Systems; Beerse, Belgium; reference value of $<200 \mathrm{ng} / \mathrm{ml}$ ), a marker of in vivo fibrinolysis. ${ }^{41}$

Statistical analysis of data was performed by binomial probability distribution (two tailed exact test). ${ }^{42}$ The differences in sensitivity and specificity were assessed by the $\chi^{2}$ test and Fischer's exact test for independence. The measures of association of anticardiolipin antibody subclasses and aPTT, KCT, dRVVT and dilute aPTT were taken as continuous values and evaluated by the Kendall $\tau$ correlation test.

\section{Results}

Among the 53 patients with SLE, 24 (45\%) had one or more clinical events related to thrombotic phenomena: nine $(17 \%)$ subjects had thrombophlebitis, five $(9 \%)$ had had a stroke, and $14(26 \%)$ in whom obstetric pathology was excluded, had miscarriages in the first or second trimester; four patients had more than one clinical event (table 1). Twenty nine patients $(55 \%)$ had no history of thromboses or miscarriages. Among all patients, $23(43 \%)$ had a prolonged dilute aPTT, $14(26 \%)$ prolonged dRVVT, 13 (24.5\%) prolonged KCT, five
(9.5\%) prolonged aPTT and $22(41 \%)$ showed increased titres of circulating anticardiolipin antibodies.

In patients with a history of thrombosis or miscarriage the dilute aPTT was prolonged in 19 subjects $(79 \%)$, while dRVVT was abnormal in 12 cases $(50 \%)$. In all patients with prolonged dilute aPTT and dRVVT the confirmatory procedure with $0.05 \mathrm{mM}$ PS/PC liposomes normalised the coagulation time (data not shown). KCT and aPTT were prolonged in $11(46 \%)$ and five $(21 \%)$ patients, respectively. In the same subgroup the anticardiolipin antibody titres were increased in 13 (54\%) subjects (table 1 ).

Among the 29 patients without a history of thrombosis or miscarriages, a prolonged dilute aPTT was found in four subjects, while dRVVT and KCT were abnormal in two patients. In two of these subjects with prolonged diluted aPTT and dRVVT the confirmatory test with PS/PC liposomes corrected the coagulation time (data not shown). In this subgroup there were no patients with prolonged aPTT, but nine subjects with SLE without thrombotic episodes showed high circulating titres of anticardiolipin antibodies (table 2).

In all patients the high concentrations of anticardiolipin antibodies were especially dependent on the presence of high titres of circulating anticardiolipin IgG antibodies, which were found in $86.4 \%$ compared with $27.3 \%$ of anticardiolipin IgM antibodies and $22.7 \%$ of anticardiolipin IgA antibodies (tables 1 and 2).

The sensitivity and the specificity of the dilute aPTT, dRVVT, KCT, aPTT and anticardiolipin antibody titres for thrombotic

Table 1 aPTT, KCT, dRVVT, dilute aPTT and anticardiolipin antibodies in patients with thrombosis, miscarriage, or both

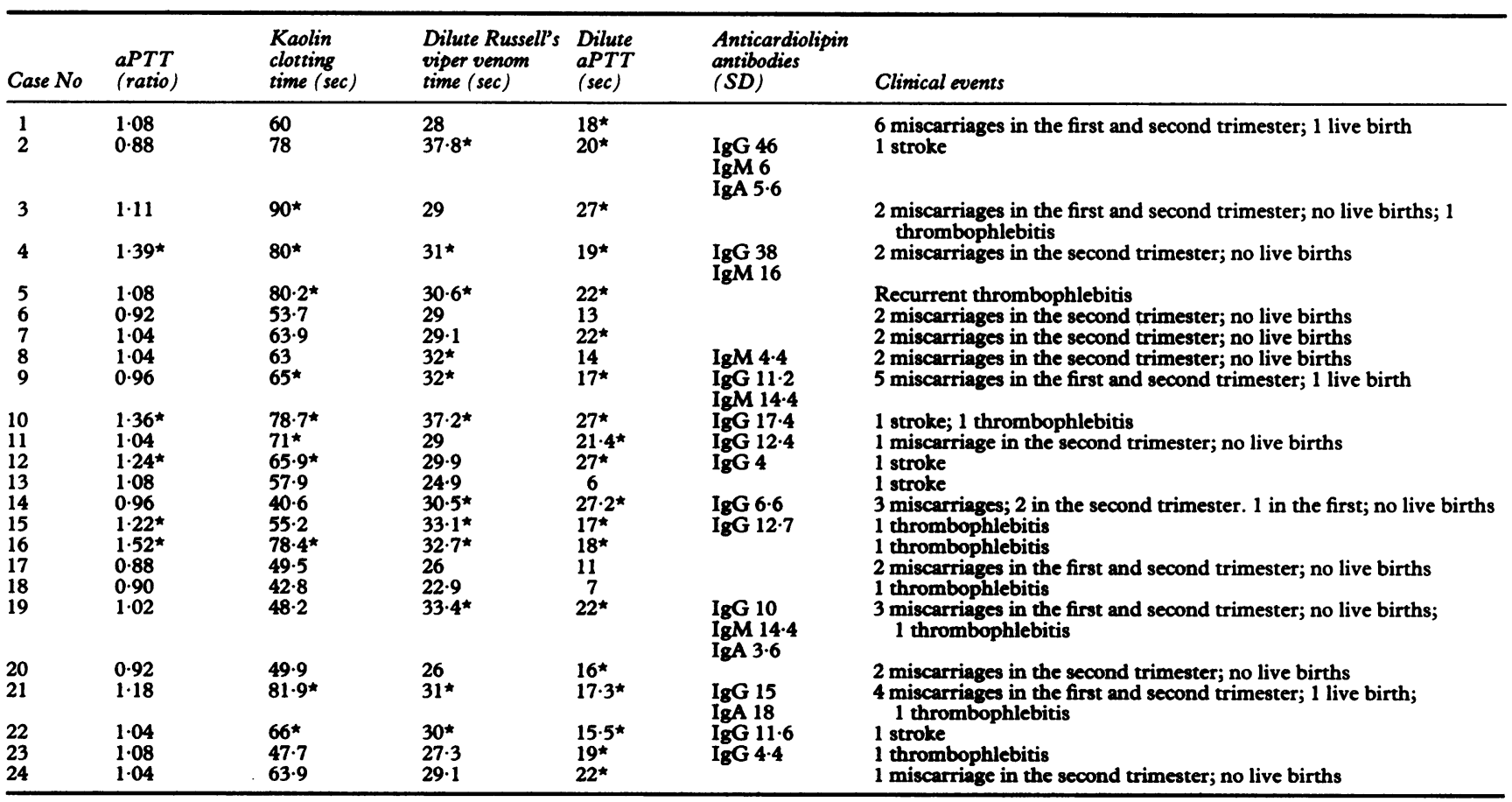

^Abnormal values. 
Table 2 aPTT, KCT, dRVVT, dilute aPTT and anticardiolipin antibodies in patients with thrombosis or miscarriage

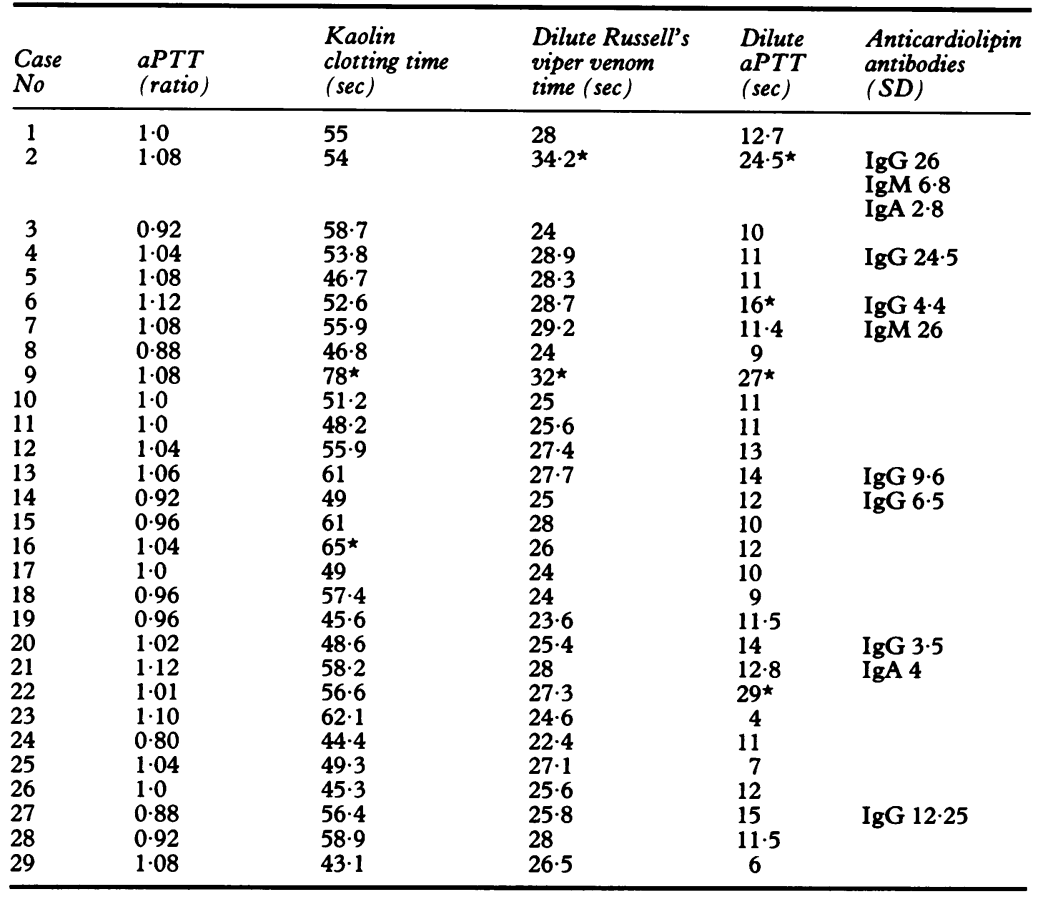

*Abnormal values.

events and miscarriages are shown in table 3.

The prolonged dilute aPTT was more sensitive than the dRVVT $(79 \%$ v $50 \%$; $\mathrm{p}<0.05)$, KCT $(79 \%$ v 45.8\%; p < 0.01), aPTT $(79 \%$ v 20.8\%; p < 0.001). No significant differences were found between dilute aPTT and anticardiolipin antibody titres.

The dRVVT, KCT, and anticardiolipin antibodies antibody titres were more sensitive than aPTT $(50 \%$ v $20.8 \%, \mathrm{p}<0.05 ; 45.8 \%$ v

Table 3 Sensitivity and specificity to thrombosis and miscarriages of aPTT, dilute aPTT, dRVVT, KCT and anticardiolipin antibodies

\begin{tabular}{|c|c|c|c|}
\hline Assays & $\begin{array}{l}\text { Sensitivity } \\
\text { ( } 95 \% \text { confidence } \\
\text { intervals) } \\
n=24 \\
\%\end{array}$ & $\begin{array}{l}\text { Specificity } \\
\text { (95\% confidence } \\
\text { intervals) } \\
n=29 \\
\%\end{array}$ & tp Value \\
\hline Dilute aPTT & $\begin{array}{l}79(19 / 24) \\
(57 \cdot 85-92 \cdot 87)\end{array}$ & $\begin{array}{l}86 \cdot 2(25 / 29) \\
(71 \cdot 77-97 \cdot 73)\end{array}$ & $<0.001$ \\
\hline dRVVT & $\begin{array}{l}50(12 / 24) \\
(29 \cdot 12-70 \cdot 88)\end{array}$ & $\begin{array}{l}93(27 / 29) \\
(81.65-99.91)\end{array}$ & $<0.01$ \\
\hline KCT & $\begin{array}{l}45 \cdot 83(11 / 24) \\
(25 \cdot 5-67 \cdot 18)\end{array}$ & $\begin{array}{l}93(27 / 29) \\
(81.65-99.91)\end{array}$ & $<0.01$ \\
\hline aPTT & $\begin{array}{l}20 \cdot 8(5 / 24) \\
(7 \cdot 13-42 \cdot 15)\end{array}$ & $\begin{array}{l}100(29 / 29) \\
(87 \cdot 66-100)\end{array}$ & $<0.02$ \\
\hline Anticardiolipin antibodies & $\begin{array}{l}54(13 / 24) \\
(32 \cdot 82-74 \cdot 45)\end{array}$ & $\begin{array}{l}69(20 / 29) \\
(49 \cdot 17-84 \cdot 72)\end{array}$ & NS \\
\hline $\begin{array}{l}\text { Differences: } \\
\text { Dilute aPTT, dRVVT }\end{array}$ & $\begin{array}{l}29^{\star} \\
(10-47 \cdot 5)\end{array}$ & $\begin{array}{l}6 \cdot 8 \\
(-2-16)\end{array}$ & \\
\hline Dilute aPTT, KCT & $\begin{array}{l}33 \cdot 2^{\star \star} \\
(13 \cdot 9-52 \cdot 4)\end{array}$ & $\begin{array}{l}6 \cdot 8 \\
(-2-16)\end{array}$ & \\
\hline Dilute aPTT, aPTT & $\begin{array}{l}58 \cdot 2 \star \star \star \\
(38 \cdot 1-78 \cdot 3)\end{array}$ & $\begin{array}{l}13 \cdot 8 \\
(1-26 \cdot 6)\end{array}$ & \\
\hline $\begin{array}{l}\text { Dilute aPTT, anticardiolipin } \\
\text { antibodies } \\
\text { KCT, aPTT }\end{array}$ & $\begin{array}{l}25 \\
(7 \cdot 3-42 \cdot 6) \\
25^{\star} \\
(7 \cdot 3-42 \cdot 67)\end{array}$ & $\begin{array}{l}17 \cdot 2 \\
(3-31 \cdot 2) \\
7 \\
(-2 \cdot 5-16)\end{array}$ & \\
\hline dRVVT, aPTT & $\begin{array}{l}29 \cdot 2^{\star} \\
(10 \cdot 6-47 \cdot 7)\end{array}$ & $\begin{array}{l}7 \\
(-2 \cdot 5-16)\end{array}$ & \\
\hline dRVVT, KCT & $\begin{array}{l}4 \cdot 2 \\
(-4-12 \cdot 4)\end{array}$ & $\begin{array}{l}0 \\
(0-0)\end{array}$ & \\
\hline $\begin{array}{l}\text { Anticardiolipin antibodies, } \\
\text { aPTT } \\
\text { Anticardiolipin antibodies, } \\
\text { dRVVT } \\
\text { Anticardiolipin antibodies, } \\
\text { KCT }\end{array}$ & $\begin{array}{l}25 \cdot 2^{\star} \\
(7 \cdot 47-43) \\
4 \\
(-4-12) \\
8 \cdot 2 \\
(-3-19 \cdot 4)\end{array}$ & $\begin{array}{l}31 \star \star \\
(13 \cdot 8-48 \cdot 2) \\
24^{\star} \\
(8 \cdot 1-39 \cdot 9) \\
24 \\
(8 \cdot 1-39 \cdot 9)\end{array}$ & \\
\hline
\end{tabular}

Parentheses contain $95 \%$ confidence intervals calculated with the binomial distribution for sensitivities and specificities and with normal approximation for differences.

$\star=\mathrm{p}<0.05 ;{ }^{\star \star}=\mathrm{p}<0.01 ;{ }^{\star \star \star}=\mathrm{p}<0.001$

$\dagger \chi^{2}$ with continuity correction or (if $n<5$ ) Fisher's exact test.
$20.8 \%, \mathrm{p}<0.05 ; 54 \%$ v 20.8\%, $\mathrm{p}<0.05$, respectively). No significant differences in sensitivity were found between the dRVVT, $\mathrm{KCT}$, and anticardiolipin antibodies titres (table 3).

aPTT was more specific to thrombotic events and miscarriages than dilute aPTT, dRVVT, and KCT, but the differences were not significant. aPTT and dRVVT, on the contrary, were significantly more specific than anticardiolipin antibody titres $(\mathrm{p}<0.01 ; \mathrm{p}<0.05$, respectively) (table 3).

The analysis of cross classification data shows a significant association between thrombotic episodes or miscarriages, or both, and the abnormality of dilute aPTT $(\mathrm{p}<0.0001)$, dRVVT $(\mathrm{p}<0.01)$, KCT $(\mathrm{p}<0.01)$ and aPTT $(\mathrm{p}<0.02)$. No significant association was found between clinical events and anticardiolipin antibody titres (table 3).

In all patients with presumed thrombotic events further analysis was carried out distinguishing patients with arterial and venous thrombosis from those with miscarriages alone. In the group of patients $(n=13)$ with arterial and venous thromboses we found a significant correlation between clinical events and abnormal dilute aPTT $(p<0.0001)$, dRVVT $(\mathrm{p}<0.001), \quad$ KCT $\quad(\mathrm{p}<0.001), \quad$ aPTT $(\mathrm{p}<0.01)$, and anticardiolipin antibody titres $(p<0.05)$, respectively (table 4$)$.

In the group of patients with miscarriages alone we found a significant association between clinical events, dilute aPTT $(p<0.001)$ and dRVVT $(p<0.05)$ (table 5).

The correlation between laboratory tests that screen for lupus anticoagulant and anticardiolipin antibody titres was also studied. Dilute aPTT and dRVVT were the only tests that significantly correlated with anticardiolipin antibodies, in particular with anticardiolipin IgG titres (table 6).

In all patients, the evaluation of circulating concentrations of D-Dimer showed normal values $(<200 \mathrm{ng} / \mathrm{ml})$, thus precluding intravascular clotting action.

\section{Discussion}

The natural history of patients with SLE can be complicated by thromboembolic accidents which range from $4 \cdot 5-18 \%$ of cases, ${ }^{43-46}$ while miscarriages have been reported to occur in $16 \%$ of such patients. ${ }^{47}$ Other studies, however, have shown a higher incidence of clinical events related to thrombosis in SLE. ${ }^{1148}$

A relatively high rate of arterial and venous thrombosis $(24 \%)$ and miscarriages $(26 \%)$ was found in our patients with SLE; this might be explained by a high number of lupus anticoagulant positive patients. A large variability in lupus anticoagulant positivity was related to the tests used. In fact the prevalence of lupus anticoagulant, diagnosed the revised scientific subcommittee criteria for lupus anticoagulants, ${ }^{49}$ ranged from $43 \%$, when assessed by dilute aPTT, to $9.5 \%$ when assessed by aPTT. This variable capacity to detect the presence of lupus anticoagulant probably 
Table 4 Association between venous and arterial thrombosis and abnormal laboratory tests in patients with SLE

\begin{tabular}{lcll}
\hline & $\begin{array}{l}\text { Patients with SLE } \\
\text { arterial and venous } \\
\text { thrombosis } \\
n=13\end{array}$ & $\begin{array}{l}\text { Patients with SLE } \\
\text { without } \\
\text { thrombosis } \\
n=29\end{array}$ & $\begin{array}{l}\chi^{2} \text { test with } \\
\text { continuity correction } \\
\text { or Fisher's exact test } \\
\text { p Value }\end{array}$ \\
assays & $4(31 \%)$ & $0(0 \%)$ & $<0.01$ \\
aPTT & $8(62 \%)$ & $2(7 \%)$ & $<0.001$ \\
dRVVT & $8(62 \%)$ & $2(7 \%)$ & $<0.001$ \\
KCT & $11(85 \%)$ & $4(14 \%)$ & $<0.0001$ \\
Dilute aPTT & $9(69 \%)$ & $9(31 \%)$ & $<0.05$ \\
Anticardiolipin antibodies & 9 & & \\
\hline
\end{tabular}

Table 5 Association between miscarriages and abnormal laboratory tests in patients with SLE

\begin{tabular}{|c|c|c|c|}
\hline $\begin{array}{l}\text { Abnormal } \\
\text { assays }\end{array}$ & $\begin{array}{l}\text { Patients with SLE } \\
\text { and miscarriage } \\
\text { only } \\
n=11\end{array}$ & $\begin{array}{l}\text { Patients with SLE } \\
\text { and without } \\
\text { thrombosis } \\
n=29\end{array}$ & $\begin{array}{l}\chi^{2} \text { test with } \\
\text { continuity correction } \\
\text { or Fisher's exact test } \\
p \text { Value }\end{array}$ \\
\hline $\begin{array}{l}\text { aPTT } \\
\text { dRVVT } \\
\text { KCT } \\
\text { Dilute aPTT } \\
\text { Anticardiolipin antibodies }\end{array}$ & $\begin{array}{l}1(9 \%) \\
4(36 \%) \\
3(27 \%) \\
8(73 \%) \\
4(36 \%)\end{array}$ & $\begin{array}{l}0(0 \%) \\
2(7 \%) \\
2(7 \%) \\
4(14 \%) \\
9(31 \%)\end{array}$ & $\begin{array}{l}<\mathrm{NS} \\
<0 \cdot 05 \\
<\mathrm{NS} \\
<0 \cdot 001 \\
<\mathrm{NS}\end{array}$ \\
\hline
\end{tabular}

explains the different associations found between lupus anticoagulant tests and thrombosis in our patients. In fact, dilute aPTT showed a higher sensitivity to thrombotic events, compared with aPTT, KCT, and dRVVT.

Currently, the aPTT is the test usually performed when screening for lupus anticoagulant. When the test was prolonged, the activity of clotting factors was normal and when the addition of an equal part of normal plasma did not normalise the coagulation time, the presence of lupus anticoagulant was suspected. ${ }^{9}$ In previous studies this assay showed poor sensitivity to lupus anticoagulant and did not correlate with thrombotic events in patients with SLE. ${ }^{22} 29$ The sensitivity of the aPTT to lupus anticoagulant, however, varies depending on the different reagents and test system used. ${ }^{16}$ In fact, some aPTT reagents and methods were shown to be very sensitive to lupus anticoagulant and these differences seem to be particularly the result of the nature and quantity of the phospholipid used as a platelet substitute. ${ }^{175051}$ The low sensitivity of the aPTT observed in our study may also be attributed to a poor sensitivity to lupus anticoagulant of phospholipid preparations used in the test system.

The KCT has been found to have good sensitivity to lupus anticoagulant in several recent studies, ${ }^{182}$ and its seems particularly useful in screening plasma samples from pregnant women. ${ }^{28} \mathrm{KCT}$ also utilises platelet poor plasma with no exogenous phospholipids and is then sensitive to residual platelets. ${ }^{53}$ In our study we found the KCT normal values to be shorter than those found by other authors. ${ }^{2152}$ Although PPP was obtained by double high

Table 6 Correlation of dilute aPTT, dRVVT, KCT, aPTT with anticardiolipin antibody tests

\begin{tabular}{lllll}
\hline & $\begin{array}{l}\text { Anticardiolipin } \\
\text { antibodies }\end{array}$ & IgG & $I g M$ & $I g A$ \\
\hline Dilute aPTT & $-2.19(0.03)$ & $2.67(0.01)$ & 0.08 (NS) & $0.78(\mathrm{NS})$ \\
dRVVT & $-2.58(0.01)$ & $3.21(0.02)$ & $1.05(\mathrm{NS})$ & $1.13(\mathrm{NS})$ \\
KCT & $-0.9(\mathrm{NS})$ & $1.6(\mathrm{NS})$ & $-0.6(\mathrm{NS})$ & 0.67 (NS) \\
aPTT & -1.8 (NS) & $1.43(\mathrm{NS})$ & $-0.5(\mathrm{NS})$ & 0.62 (NS) \\
\hline
\end{tabular}

The table contains $\mathrm{Z}$ and two-tailed probability for each measure of association. speed centrifugation at $5000 \times g$ for $10 \mathrm{~min}$ utes, this suggests that platelet contamination may account for the rather poor performance of this test in our study. Consequently it might be critical to remove platelets completely from plasma by a filtration step, but this may be difficult to adapt for routine screening.

The dRVVT is a coagulation test for lupus anticoagulant, based on a modified Russell's viper venom time, using limited amounts of phospholipid and venom. The dRVVT is insensitive to specific factor deficiencies caused by antibodies to factors VIII, IX, and XI.$^{24}$ Some authors showed that this test was more sensitive than aPTT and tissue thromboplastin inhibition procedure (TTI). ${ }^{24}$ It should therefore be very useful as a screening test for lupus anticoagulant. dRVVT was also described as significantly associated with past thrombotic events, like stroke and deep venous thrombosis, in patients with SLE, while no association with miscarriages was detected. ${ }^{22}$ Recent preliminary data have suggested that the sensitivity of dRVVT to lupus anticoagulant is highly variable, depending on the selection of the phospholipid for the assay..$^{54}$

Dilute aPTT, modified by Alving, ${ }^{31}$ utilises several dilutions of exogenous phospholipids added to coagulation system. ${ }^{39}$ Dilute aPTT can show that the circulating inhibitor is directed against negatively charged phospholipids. This is shown by the inverse correlation between the phospholipid content of the coagulation system and the degree of prolongation of the test. Because the procedure includes mixing patients with normal plasma, any individual or multiple coagulation factor deficiencies, such as those induced by warfarin, can be easily corrected. ${ }^{31}$

High titres of circulating anticardiolipin antibodies were also related to the presence of lupus anticoagulant. ${ }^{556}$ In fact, over the past few years, several reports have focused on a new clinical entity, the antiphospholipid syndrome, characterised by the presence of anticardiolipin antibodies, lupus anticoagulant, thrombosis and fetal loss. ${ }^{5758}$ On the other hand, recent results suggest that the patient population defined by the presence of lupus anticoagulant may be distinct from, but may overlap with the anticardiolipin antibody positive population: lupus anticoagulant and antiphospholipid antibodies seem to define two distinct but related patient populations, each associated with an increased risk of thrombosis, ${ }^{29} 59$ while the association between anticardiolipin antibody titres and recurrent miscarriage is still debated. ${ }^{60}$

In 36 patients with SLE we preliminarily found a strong association between a history of thrombotic episodes and the presence of lupus anticoagulant, demonstrated by the prolonged dilute aPTT. This association, however, was absent if lupus anticoagulant was screened by aPTT, which was abnormal in a lower percentage of patients with thrombosis. ${ }^{29}$ This supported the suggestion that the method used so far for detecting lupus anticoagulant could have underestimated the association between lupus anticoagulant and thrombosis. 
This study has shown that dilute aPTT is significantly more sensitive to thrombotic events in patients with SLE than other tests such as aPTT, KCT, and dRVVT previously shown to be diagnostic for lupus anticoagulant. In fact, among patients with SLE with past thrombotic events, the number of lupus anticoagulant positive patients was significantly higher $(79 \%)$ when a dilute aPTT diagnostic test was used. Dilute aPTT also had good specificity to thrombotic events, although this was not significantly different from the other tests examined. The dRVVT showed a good sensitivity to thrombotic phenomena, even if it was less than dilute aPTT. The dRVVT, however, had better specificity, which, according to previous reports, ${ }^{22}$ was significantly higher than the anticardiolipin antibody titre. The latter, on the contrary showed poor specificity to thrombotic events; in fact, nine patients with SLE and without a history of arterial and venous thrombosis and/or miscarriages had high values of circulating anticardiolipin antibodies.

aPTT was the most specific assay to thrombotic events; this particularly high specificity could explain its low sensitivity to lupus anticoagulant. $^{2252}$

Previous reports have shown that abnormal dRVVT and high anticardiolipin antibody titres were significantly associated with past presumed thrombotic events in patients with SLE. ${ }^{22}$ Our study extends this observation showing that the abnormality of dilute aPTT, dRVVT, KCT and aPTT was significantly related to thrombotic episodes, thus supporting the hypothesis of a striking association between lupus anticoagulant and thrombosis. ${ }^{61-64} \mathrm{High}$ titres of circulating antibodies, however, were not found to be significantly associated with presumed thrombotic events, except for a weak association found only in patients with arterial and venous thrombosis. Increased anticardiolipin antibody titres showed a good sensitivity to thrombotic phenomena which was not significantly different from dilute aPTT, but their low specificity probably accounted for a weak association with thrombosis. This confirms the data of Triplett, who did not find any correlation between the titre of circulating antiphospholipid antibodies and thrombotic complications in patients with the lupus anticoagulant. ${ }^{59}$

When the statistical analysis was performed on patients with SLE and miscarriages alone, the clinical event was associated with the abnormality of dilute aPTT and dRVVT, while no association was found with the other tests examined. This suggests that in our patients with SLE the miscarriage could have been related to the presence of lupus anticoagulant. This was not found in a previous study where only aPTT, dRVVT and anticardiolipin antibodies were used to detect lupus anticoagulant. $^{22}$ Perhaps an association between miscarriage and lupus anticoagulant can be found only using some laboratory tests that are very sensitive and specific to lupus anticoagulant. However, such an association is weaker than that found between arterial and venous thrombosis and lupus anticoagulant, indicating that other mechanism(s) could be involved in the pathogenesis of miscarriage in subjects with SLE.

Finally, anticardiolipin IgG antibodies were significantly correlated with dilute aPTT and dRVVT values, confirming previous reports. ${ }^{22} 2965$ This indicates that high circulating anticardiolipin IgG antibody titres do have a role in lupus anticoagulant events, although the poor specificity to thrombotic events suggests that other antiphospholipid antibodies are involved in lupus anticoagulant. ${ }^{.6-68}$

In summary, among some laboratory tests usually performed to istudy lupus anticoagulant, dilute aPTT, a simple and cheap coagulation assay, supported by the confirmatory procedure, was the most sensitive test to past thrombotic episodes and miscarriages in patients with SLE. The combination of this assay with a very specific test like the dRVVT could help to identify patients with lupus anticoagulant who are at high risk of thrombosis.

We thank Drs T Exner and D Triplett for their helpful comments.

Supported in part by The Andrea Cesalpino Foundation.

1 Thiagarajan P, Shapiro SS, De Marco L. Monoclonal Immunoglobulin M1 coagulation inhibitor with phospholipid specificity. Mechanism of a lupus anticoagulant. J Clin Invest 1980;66:397-405.

2 Pengo V, Thiagarajan P, Shapiro SS, Heine MJ. Immunocological specificity and mechanism of action of IgG lupus anticoagulant. Blood 1987;70:69-76.

3 Shapiro SS, Thiagarajan P. Lupus anticoagulant. In: Spaet TH, ed. Progress in hemostasis and thrombosis Vol 6. New York: Grune \& Stratton, 1982:263-85.

4 Canoso RT, Sise HS. Chlorpromazine-induced lupus anticoagulant and associated immunological abnormalities. Am J Hematol 1982;13:121-9.

5 Cohen AJ, Philips TM, Kessler CM. Circulating coagulation inhibitor in the acquired immunodeficiency syntion inhibitor in the acquired immunod
drome. Ann Intern Med 1986;104:175-80.

6 Triplett DA, Brandt JT. Lupus anticoagulant: Misnomer, paradox riddle, epiphenomenon. Hematol Pathol 1988, 2:121-43.

7 Derksen RHWM, Kater L. Lupus anticoagulant: revival of an old phenomenon. Clin Exp Rheumatol 1985;3:349-57.

8 Frick PG. Acquired circulating anticoagulants in systemic "collagen disease" Blood 1955;10:691-706.

9 Feinstein DI, Rapaport SI. Acquired inhibitor of blood coagulation. Prog Hemost Thromb 1972;1:75-95.

10 Regan, MG, Lackner H, Karpatkin S. Platelet function and coagulation profile in lupus erythematosus: studies in 50 patients. Ann Intern Med 1974;81:462-8.

11 Boey ML, Colaco CB, Gharavi AE, Elkon KB, Loizou S, Hughes GRV. Thrombosis in systemic lupus erythematosus: striking association with the presence of circulating tosus: striking association with the presence of circul
lupus anticoagulant. $\mathrm{Br} \mathrm{Med} J$ 1983;287:1021-3.

12 Exner T, Rickard KA, Kronenberg H. A sensitive test demonstrating lupus anticoagulant and its behavioural patterns. Br J Haematol 1978;40:143-51.

13 Hughes GRV, Harris EN, Gharavi AE. The anticardiolipin syndrome. J Rheumatol 1986;13:486-9.

14 Schleider MA, Nachman RL, Jaffe EA, Coleman M. A clinical study of the lupus anticoagulant. Blood 1976 48:499-509.

15 Lubbe WF, Palmer SJ, Butler WS, Liggins GC. Fetal survival after prednisone suppression of maternal lupus anticoagulant. Lancet 1983;ii:1361-3.

16 Mannucci PM, Canciani MT, Mari D, Meucci P. The varied sensitivity of partial thromboplastin and prothrombin time reagent in the demonstration of the lupus-like time reagent in the demonstration of the lup
anticoagulant. Scand J Haematol 1979;22:423-32.

17 Brandt JT, Triplett DA, Musgrave K, Orr C. The sensitivity of different coagulation reagent to the presence of sitivity of different coagulation reagent to the presence of lipus 4 .

18 Lesperance B, David M, Rauch J, Infante-Rivard C, Rivard GE. Relative sensitivity of different tests in the detection of low titer lupus anticoagulants. Thromb Haemostas 1988 60:217-9.

19 Triplett DA, Brandt JT, Maas RL. The laboratory heterogeneity of lupus anticoagulants. Arch Pathol Lab Med 1985;109:946-51.

20 Lazarchick J, Kizer J. The laboratory diagnosis of lupus anticoagulants. Arch Pathol Lab Med 1989;113:177-80. 
21 Exner T, Papadopoulos G, Koutts J. Use of a simplified dilute Russell's viper venom time (dRVVT) confirms heterogeneity among "lupus anticoagulants". Blood Coagulation and Fibrinolysis 1990;1:259-66.

22 Petri M, Rheinschmidt M, Whiting-O'Keefe Q, Hellmann $D$, Corash $\mathrm{L}$. The frequency of lupus anticoagulant in systemic lupus erythematosus. Ann Intern Med 1987;106: 524-31.

23 Gastineau DA, Kazmier FJ, Nichols WL, Bowie EJW. Lupus anticoagulant: an analysis of the clinical and laboratory features of 219 cases. Am J Hematol 1985; laboratory

24 Thiagarajan P, Pengo V, Shapiro SS. The use of dilute Russell's viper venom time for the diagnosis of lupus Russell's viper venom time for the

25 Lechner K. Lupus anticoagulant and thrombosis. In: Verstrate M, Vermylen J, Lijnen R, Arnout J, eds. Thrombosis and haemostasis. Leuven, Belgium: Leuven University Press, 1987:525-47.

26 Jungers P, Liote F, Dautzenberg MD, et al. Lupus anticoagulant and thrombosis in systemic lupus erythematosus. Lancet 1984;ii:574-5.

27 Branch DW. Immunologic disease and fetal death. Clin Obstet Gynecol 1987;30:295-311.

28 Lubbe WE, Liggins GC. Role of anticoagulant and autoimmunity in recurrent pregnancy loss. Semin Reprod Endocrinol 1988;6:181-90.

29 Ferro D, Saliola M, Quintarelli C, Carlucci M, Valesini G, Violi F. Specificity and sensitivity of dilute aPTT and anticardiolipin antibodies towards thrombosis and miscarriage in patients with systemic lupus erythematosus. Thromb Res 1990;59:609-17.

30 Derksen RHWM, Hasselaar P, Blokzijl L, Frits HS, Meyling G, Degroot P. Coagulation screen is more specific than the anticardiolipin antibody ELISA in defining a thrombotic subset of lupus anticoagulants. Ann Rheum Dis 1988;47:364-71.

31 Alving BM, Baldwin PE, Richards RL, Jackson BJ. The dilute phospholipid aPT T: a sensitive assay for verification of lupus anticoagulants. Thromb Haemostas 1985;54: 709-12.

32 Harris EN, Loizou S, Englert H. Anticardiolipin antibodies and lupus anticoagulant. Lancet 1984;ii:1099.

33 Violi F, Valesini G, Ferro D, Tincani A, Balestrieri G, Balsano F. Anticoagulant activity of anticardiolipin antibodies. Thromb Res 1986;44:543-8.

34 Loizou S, McCrea JD, Rudge AC, Reynolds R, Boyle CC, Harris EN. Measurement of anti-cardiolipin antibodies by an enzyme-linked immunosorbent assay (ELISA): standardization and quantitation of results. Clin Exp Immunol 1985;62:738-45.

35 Harris EM. Solid-phase anti-cardiolipin test revisited. $A m J$ Med 1988;85:599-600.

36 Tan EN, Choen AS, Fries JF, et al. The 1982 revised criteria for the classification of systemic lupus erythematosus. Arthritis Rheum 1982;25:1271-8.

37 Margolis J. The kaolin clotting time: a rapid one stage method for diagnosis of coagulation defects. J Clin Pathol 1958;11:406-9.

38 Violi F, Ferro D, Valesini G, Quintarelli C, Balsano F. Lupus anticoagulant in liver cirrhosis. Thromb Haemostas 1988;59:335-6.

39 Violi F, Ferro D, Quintarelli C, et al. Dilute aPTT prolongation by antiphospholipid antibodies in patients with liver cirrhosis. Thromb Haemostas 1990;63:183-6.

40 Valesini G, Harris EN, Tincani A, et al. Use of monoclonal antibodies to idenify shared idiotypes on anticardiolipin and anti-DNA antibodies in human sera. Clin Exp Rheumatol 1987;70:18-25.

41 Violi F, Ferro D, Quintarelli C, Alessandri C. Evaluation of D-Dimer in patients with liver cirrhosis. Thromb Haemostas 1989;62:1149-50.

42 Colton T. Statistics in medicine. Boston: Little, Brown and Company, 1985:165-75.

43 Angles-Cano E, Sultan Y, Clavel JP. Predisposing factors to thrombosis in systemic lupus erythematosus. J Lab Clin Med 1979;94:312-23.

44 Prentice RL, Gatenby PA, Loblay RH, Shearman RP, Kronenberg $\mathrm{H}$, Basten A. Lupus anticoagulant in preg- nancy. Lancet 1984;ii:464.

5 Dubois EL. Lupus erythematosus. 2nd ed. Los Angeles University of Southern California Press, 1974.

46 Peck B, Hoffman GS, Franck WA. Thrombophlebitis in systemic lupus erythematosus. JAMA 1978;240:1728-30.

47 Ramsey-Goldeman R. Pregnancy in systemic lupus erythematosus. Rheum Dis Clin North Am 1988;14:169-85.

48 Derksen RhWM, Bouma BN, Kater L. The striking association between lupus anticoagulant and fetal loss in systemic lupus erythematosus patients. Arthritis Rheum 1986; 29:695-6.

49 Exner T, Triplett DA, Taberner D, Machin SS. Guideline for testing and revised criteria for lupus anticoagulants. SSC Subcommittee for the standardization of lupus Anticoagulants). Thromb Haemostas 1991;65:320-2.

50 Stevenson KJ, Easton AC, Curry A, Thomson JM, Poller L. The reliability of activated partial thromboplastin time methods and the relationship to lipid composition and ultrastructure. Thromb Haemostas 1986;55:250-8.

51 Brandt JT, Triplett DA, Rock WA, Bovill EG, Arkin CF Effect of lupus anticoagulants on the activated partial thromboplastin time. Results of the college of American Pathologist survey program. Arch Pathol Lab Med 1991; 115:109-14.

52 Lo SCL, Oldemeadow MJ, Howard MA, Firxin BG. Comparison of laboratory tests used for identification of Comparison of laboratory tests used for identification of

53 Exner $\mathrm{T}$. Comparison of two simple tests for the lupus anticoagulant. Am J Clin Pathol 1985;83:215-8.

54 Triplett DA, Brandt J. Laboratory identification of the lupus anticoagulant. Br J Haematol 1989;73:139-42.

55 Harris EN, Gharavi AE, Boey ML, et al. Anticardiolipin antibodies: detection by radioimmunoassay and association with thrombosis in systemic lupus erythematosus. Lancet 1983;ii:1211-4.

56 Mackworth-Young CG, Loizou CG, Walport MJ. Antiphospholipid antibodies and disease. $Q J$ Med 1989 72:767-77.

57 Harris EN, Chan SHK, Asherson RA, Aber VR, Gharav AE, Hughes GRV. Thrombosis recurrent fetal loss and thrombocytopenia: predictive value of the anticardiolipin thrombocytopenia: predictive value of the anticardiolit

58 Locksin MD, Druzin ML, Goei S. Antibody to cardiolipin as a predictor of fetal distress or death in pregnant patients
with systemic lupus erythematosus. $N \mathrm{Engl} \mathrm{J} \mathrm{Med}$ with systemic lup

59 Triplett DA, Brandt JT, Musgrave KA, Orr CA. The relationship between lupus anticoagulants and antibodies to phospholipid. JAMA 1988;259:550-4

60 Triplett DA. Antiphospholipid antibodies and recurrent pregnancy loss. Am J Reprod Immunol 1989;20:52-67.

61 Hughes GRV. Thrombosis, abortion, cerebral disease, and the lupus anticoagulant. $\mathrm{Br}$ Med $J$ 1983;287:1088-9.

62 Glueck HI, Kant KS, Weiss MA, Pollak VE, Miller MA Coots $M$. Thrombosis in systemic lupus erythematosus: relation to the presence of circulating anticoagulant. Arch relation to the presence of circulat

63 Violoi F, Ferro D, Valesini G, et al. High levels of tissueplasminogen activator inhibitor in patients with systemic
lupus erythematosus and thrombosis. Br Med J 1990; lupus erythem

64 Love EP, Santoro SA. Antiphospholipid antibodies: anticardiolipin and the lupus anticoagulant in systemic lupus erythematosus (SLE) and in non-SLE disorders. Ann Int Med 1990;112:682-98.

65 Alving BM, Barr CF, Tang DB. Correlation between lupus Anticoagulants and anticardiolipin antibodies in patients with prolonged activated partial thromboplastin time. $\mathrm{Am}$ J Med 1990;88:112-6.

66 Thiagarajan P, Shapiro SS. Lupus anticoagulants. In Colman RW, ed. Disorders of thrombosisformation. New York: Churchill Livingstone, 1984:101-8.

67 Staub HL, Harris EN, Khamashta MA, Savidge G, Chahade WH, Hughes GRV. Antibody to phosphatidylethanolamine in a patient with lupus anticoagulant and lethanolamine in a patient with lupus anticoa

68 Exner T, McRea J. Studies on the relationship between "antiphospholipid antibodies and the lupus anticoagulant". Blood Coagulation and Fibrinolysis. 1990;1:17-21. 